\title{
Fertility-conserving treatment of early stage cervical cancer using trachelectomy and laparoscopic lymphadenectomy-a case report and a review of recent literature
}

\author{
Markus Hahn • Wolfgang Zubke • Burkhard Schauf • \\ Karl Sotlar • Christian Gall • Bernhard Krämer • \\ Diethelm Wallwiener • Ute Krainick-Strobel
}

Received: 16 July 2007 / Accepted: 18 July 2007 / Published online: 15 August 2007

(C) Springer-Verlag 2007

\begin{abstract}
Fertility-conserving surgical treatment of patients with early stage cervical cancer poses a particular challenge. In specialist centres, trachelectomy with laparoscopic lymphadenectomy could be established as a minimally invasive, fertilitypreserving alternative to radical hysterectomy for women of child-bearing age. This report describes the case of a 33-yearold patient who wished to conceive and was diagnosed with cervical cancer stage pT1al in 2004. The patient conceived 9 months after surgery and gave birth to a healthy baby girl at $38+0$ weeks. Complications during pregnancy were gestational diabetes, premature contractions and pre-eclampsia at 37 weeks. The advantages and disadvantages of this method as well as the specific ante-natal monitoring required are discussed.
\end{abstract}

Keywords Trachelectomy · Cervical cancer .

Fertility-conserving treatment

\section{Introduction}

With an incidence of 12 per 100,000, and peak occurrences at between 35-39 years and 60-64 years of age, cancer of

M. Hahn • W. Zubke · B. Schauf • C. Gall • B. Krämer •

D. Wallwiener $\cdot$ U. Krainick-Strobel

Obstetrics and Gynecology, University of Tuebingen,

Tuebingen, Germany

\section{K. Sotlar}

Pathology, University of Tuebingen,

Tuebingen, Germany

M. Hahn $(\bowtie)$

Calwerstr.7,

72076 Tuebingen, Germany

e-mail: 101268@online.de the cervix is also an oncological disorder of young women of child-bearing age. It is necessary to find the balance between oncological safety and fertility-preserving surgical treatment, especially for young women. Guidelines for the stage-dependant surgical treatment of cervical cancer allow radical trachelectomy up to stage FIGO Ib1.

According to the literature, the conception rate following trachelectomy lies between $40-70 \%$ [1].

The medical care of these pregnancies, especially the monitoring for those at risk of a premature delivery, poses a particular challenge.

This case report describes the course of disease of a 33year-old patient (gravida 1, para 0 , history of an elective abortion), who was diagnosed with early stage cancer of the cervix. The patient had a definite desire to conceive and therefore wished to undergo fertility-preserving treatment. Due to the early stage of the disease, a trachelectomy with laparoscopic lymph node sampling could be safely performed. Eight months postoperatively, pregnancy was confirmed, and the patient gave birth to a healthy baby girl by caesarean section in week $38+0$.

The pregnancy was complicated by a threat of premature delivery in week 29 , as well as gestational diabetes and pre-eclampsia which were diagnosed in week 37 .

\section{Course of events}

Colposcopy

The patient first presented in the dysplasia clinic of the Universitäts-Frauenklinik Tübingen in June 2004 because of a PAP IVa cervical smear. A colposcopic biopsy from this 
area histologically confirmed a CIN III with questionable microinvasion. Because an invasive cancer of the cervix could not be confirmed through the biopsy alone, a cone biopsy with dilatation and curettage (D\&C) followed in July 2006. A severe squamous-cell dysplasia with transition to a carcinoma in situ (CIN III) was found in the portio cone biopsy, as well as parts of a micro-invasive keratinised squamous cell carcinoma. The invasive portion exhibited an invasive depth of $2 \mathrm{~mm}$ and a surface area of $4 \mathrm{~mm}$. The endocervical resection area was clear; however the dysplastic cells reached up to the ectocervical resection margin.

Trachelectomy with lymph node sampling

R1 resection of the invasive part of the cone biopsy confirmed the need for further surgical treatment. Further clinical and imaging diagnostic procedures (vaginal ultrasound and MR urography) excluded infiltration of adjacent structures [2].

After the various treatment options were explained to the patient, she chose the option of trachelectomy including laparoscopic lymph node sampling. Besides the oncological safety of the method, the definite desire to conceive was important to her in her decision.

The operation was performed without complications (Fig. 1).

A laparascopic pelvic lymphadenectomy, similar to the classic Wertheim procedure, was performed to begin with. The patient was then repositioned in the lithotomy position. This was followed by high incision of the portio in analogy with the procedure according to Schauta in order to obtain a vaginal cuff. The ureter was then held back and the descending branch of the uterine artery was ligated.

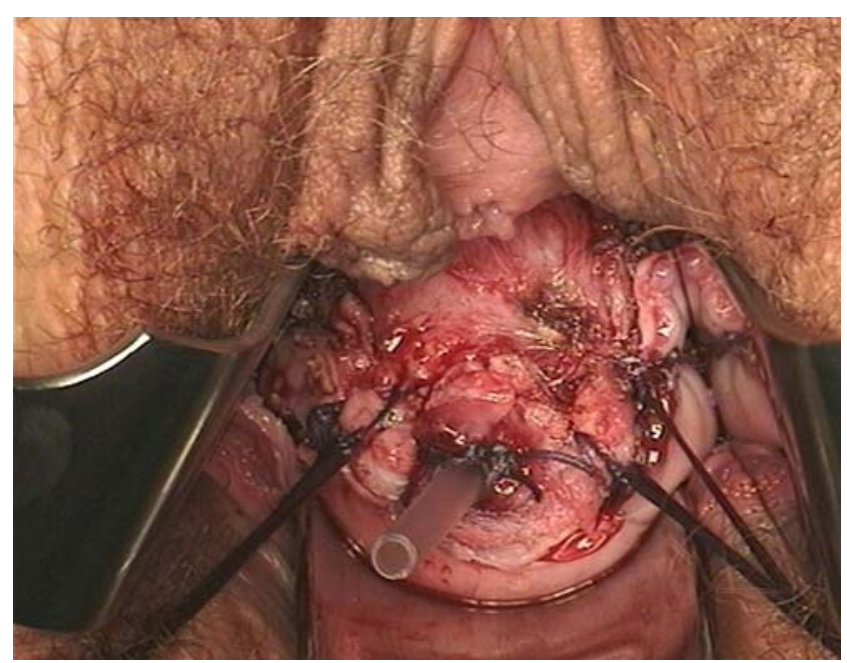

Fig. 1 To avoid adhesions and to reform the cervical canal a tube is placed inside
Amputation of the cervix about $10 \mathrm{~mm}$ cranial to the cone biopsy including the parametrium border was performed as for a modified radical trachelectomy. Finally, the vaginal tissue was fixed to the portio stump with sutures according to Sturmdorf.

Histological examination of the trachelectomy preparation showed ectocervical dysplastic areas and no further tumours. All regional lymph nodes were tumour free. Douglas cytology was also unsuspicious.

Final tumour staging included pT1a1, G1-2, pN0, M0, L0, V0 and R0.

Further recommendations of the interdisciplinary tumour board were regular follow-up appointments without further treatment.

Follow-up

The remaining cervical canal reformed well. There were no menstrual cycle disturbances and the patient was eumenorrheic. Up to now, there is no suspicion of recurrence.

\section{Pregnancy progress}

In May 2005, 9 months after the trachelectomy, the patient's gynaecologist diagnosed an intact pregnancy. The first trimester progressed without complications. From week 24 , the pregnancy was closely monitored. In week 19 gestational diabetes was diagnosed and treated by diet alone.

To prevent hyaline membrane disease, corticosteroids were administered in week 29 . This was necessary due to preterm contractions and cervical shortning without the sonographic appearance of cervical funnel development. Therefore she was treated with oral magnesium and intermittent oral fenoterol.

Ultrasound consistently showed eutrophic foetal growth with normal amniotic fluid volume up to week $37+5$. Prenatal Doppler sonography was not pathological at any time.

From week 33 pregnancy-induced hypertension developed. This was successfully controlled with methyldopa.

In week $37+6$, the patient presented with reduced amniotic fluid volume. Within $24 \mathrm{~h}$, pre-eclampsia had developed (SIH + proteinuria) with increasing oedema and epigastric discomfort. The average blood pressure measurement was $150 / 90 \mathrm{mmHg}$. An increase in liver function tests (LFTs) and a reduction in platelets were consistent with acute HELLP syndrome.

For this reason, a caesarean section was performed, and a healthy baby girl was delivered, weighing $2,780 \mathrm{~g}$, length $47 \mathrm{~cm}$ and head circumference $33 \mathrm{~cm}$.

Postpartum progress of both mother and baby was without complications. 


\section{Discussion}

The incidence of cervical cancer in Germany in 2001 was 12 per 100,000 . The incidence of preinvasive carcinomas in women of child-bearing age appears to be increasing [3]. The mean age at first diagnosis has decreased over the last 25 years by 14 years [4], with the mean age at diagnosis now being 52.2 years. The age distribution peaks between 35 and 39 years of age, and again between 60 and 64 years. These epidemiological variations explain why fertilitypreserving treatment of cervical cancer is now more often required [5-8].

It is essential to find the balance between oncological safety and a possible pregnancy $[9,10]$. Radical trachelectomy, first described by Dargent in 1987, where the cervix with the upper vaginal cuff as well as the paracervical and paracolpal tissue are resected, fulfils these requirements [11-14].

The conception rate is given as $40-70 \%$ in the literature [1].

Of couples who have planned a pregnancy after trachelectomy, $25-30 \%$ do not succeed. The main reason for this may be postoperative changes in the cervical area (changes in the cervical mucous and cervical stenoses) [15].

The pregnancy itself should be classified as a high-risk pregnancy and should therefore be monitored by the local gynaecologist in cooperation with a specialist perinatal centre [16].

The miscarriage rate in the 1 st trimester is $21 \%$, and is therefore not higher than that of the normal population [16]; the rate is $8 \%$ in the 2 nd trimester [1]. The probability of a premature delivery (before 36 weeks) is stated as $29 \%$ in the literature [1].

A reason for the possibility of premature delivery is iatrogenic cervical incompetence due to interoperative shortening of the cervix. Diagnosis of cervical incompetence by palpation and inspection of the "neocervix" alone as part of the pregnancy monitoring is not sufficient. Vaginal sonography of the cervix from week 14 of pregnancy should therefore be performed.

A further reason for premature delivery is preterm rupture of the foetal membranes as a result of chorionamnionitis. Women who received prophylactic cerclage at the time of the primary operation are especially at risk $[15,17$, 18]. There is no barrier to ascending bacteria due to the absence of protective cervical mucous after trachelectomy, and the allogenic sutures can become colonised. To solve this problem, Dargent [13] considered complete closure of the cervix according to Saling [19].

In the case described by us, cerclage was not performed at the time of the primary operation, or during pregnancy.

Plante et al. [16], whose results show a significantly reduced miscarriage rate in comparison to that in the literature, substantiated this by leaving a cervix remnant of approximately $1 \mathrm{~cm}$ in length, if oncologically feasible. This provided an adequate barrier to ascending microorganisms and therefore protection from preterm rupture of membranes.

Regarding oncological safety, in the early stages of cervical cancer trachelectomy is sufficiently reliable with a relapse rate of $4-5 \%$, and is comparable to the relapse rate after radical hysterectomy [20-25]. However, additional risk factors (haemangiosis, lymphangiosis, positive lymph node status and tumour size $>2 \mathrm{~cm}$ ) should be excluded.

Extensive resection of the parametrium was avoided and a simple modified radical trachelectomy was performed in the above stage 1al case. The modified radical trachelectomy corresponds to the recommendations made by Rob et al. [26], and it must be noted that these recommendations were published about 3 years after we performed the procedure and therefore could not be referred to for our procedure. We feel that our decision to go ahead with the modified procedure was confirmed by the above-named authors.

Trachelectomy according to Dargent is a typical combined laparascopic/vaginal operation. The laparascopic component includes pelvic lymphadenectomy; the vaginal component includes the removal of the cervical tissue, which in the original version of the first author of the procedure included the resection of the parametrium. A combined abdominal/vaginal approach would also be possible with severe intraperitoneal adhesions. We did not choose a purely vaginal approach without pelvic lymphadenectomy because the final staging of the disease had not been confirmed at the time of the trachelectomy. The twosided concept described by Rob et al. [26] with initial pelvic lymphadenectomy followed by removal of a large cone or simple vaginal trachelectomy, seems reasonable. Further prospective randomised studies are needed in this area. Taking into consideration the above-mentioned aspects, a mere resection of a large cone can be discussed. In order to further reduce the radical approach, sampling including the sentinel node concept can also be borne in mind. Sampling alone does not yet seem justifiable to us, even when in some radical lymphadenectomies only a few lymph nodes can be removed. The two-sided approach, with an initial pelvic lymphadenectomy followed by the vaginal phase of the operation in a second session after final histological assessment of the biopsy, has positive aspects. However, it involves more organisational and financial expenditure for the hospital and in our opinion should only be chosen when the immediate sectioning diagnosis appears to be unreliable. We therefore consider a single procedure to be justifiable.

The laparoscopic lymphadenectomy described in this case report was well tolerated by the patient. An advantage of the laparoscopic approach was the clear presentation of 
the anatomical structures [20,27]. Clear presentation of the individual nerves afforded minimal postoperative morbidity from rectum and bladder innervation.

\section{Conclusion}

1. Whilst taking oncological safety into account, fertility conserving treatment can be and should be carried out for young women with cervical cancer;

2. Delivery of a healthy, developed infant, near to the expected due date, is realistic.

\section{References}

1. Boss EA et al (2005) Pregnancy after radical trachelectomy: a real option? Gynecol Oncol 99(3 Suppl 1):S152-S156

2. Heyer $\mathrm{H}$ et al (2006) Selective pre-treatment diagnostic imaging for the detection of distant metastases in cervical cancer. Geburtsh Frauenheilk 66:585-590

3. Blohmer JU et al (1999) Increased incidence of cervical intraepithelial neoplasia in young women in the Mitte district, Berlin, Germany. Acta Cytol 43(2):195-200

4. Angel C, DuBeshter B, Lin JY (1992) Clinical presentation and management of stage I cervical adenocarcinoma: a 25 year experience. Gynecol Oncol 44(1):71-78

5. Gershenson DM (2005) Fertility-sparing surgery for malignancies in women. J Natl Cancer Inst Monogr 34:43-47

6. Michniewicz K, Elling D (2002) Malignant gynecologic tumors during pregnancy. A review. Geburtsh Frauenheilk 62:125-130

7. Seli E, Tangir J (2005) Fertility preservation options for female patients with malignancies. Curr Opin Obstet Gynecol 17 (3):299-308

8. Iftner T (2006) Onkologie. Zervixkarzinom: Chancen und Risiken des Früherkennungsprogramms. Geburtsh Frauenheilk 66:196-198

9. Hertel $\mathrm{H}$ et al (2001) Fertility after radical trachelectomy in patients with early stage cervical cancer. Geburtsh Frauenheilk 61:117-120

10. Hertel H, Köhler C, Schneider A (2003) Radikale Trachelektomie: Prospektive Evaluierung von 41 Patientinnen mit Zervixfrühkarzinom. Geburtsh Frauenheilk 63:63

11. Dargent D (2001) Radical trachelectomy: an operation that preserves the fertility of young women with invasive cervical cancer. Bull Acad Natl Med 185(7):1295-1304; discussion 1305-6
12. Dargent D et al (2002) Extended trachelectomy relapse: plea for patient involvement in the medical decision. Bull Cancer 89 (12):1027-1030

13. Dargent D et al (2000) Laparoscopic vaginal radical trachelectomy: a treatment to preserve the fertility of cervical carcinoma patients. Cancer 88(8):1877-1882

14. Dargent D, Mathevet P (1995) Schauta's vaginal hysterectomy combined with laparoscopic lymphadenectomy. Baillieres Clin Obstet Gynaecol 9(4):691-705

15. Bernardini $M$ et al (2003) Pregnancy outcomes in patients after radical trachelectomy. Am J Obstet Gynecol 189(5):1378-1382

16. Plante M, Renaud MC, Roy M (2005) Radical vaginal trachelectomy: a fertility-preserving option for young women with early stage cervical cancer. Gynecol Oncol 99(3 Suppl 1):S143-S146

17. Shepherd JH, Mould T, Oram DH (2001) Radical trachelectomy in early stage carcinoma of the cervix: outcome as judged by recurrence and fertility rates. Bjog 108(8):882-885

18. Petignat $P$ et al (2004) Pregnancy after trachelectomy: a high-risk condition of preterm delivery. Report of a case and review of the literature. Gynecol Oncol 94(2):575-577

19. Saling E (1984) Prevention of habitual abortion and prematurity by early total occlusion of the external os uteri. Eur J Obstet Gynecol Reprod Biol 17(2-3):165-170

20. Schneider A et al (1996) Preserving fertility in early cervix carcinoma: trachelectomy with laparoscopic lymphadenectomy. Zentralbl Gynakol 118(1):6-8

21. Burnett AF et al (2003) Radical vaginal trachelectomy and pelvic lymphadenectomy for preservation of fertility in early cervical carcinoma. Gynecol Oncol 88(3):419-423

22. Burnett AF (2006) Radical trachelectomy with laparoscopic lymphadenectomy: review of oncologic and obstetrical outcomes. Curr Opin Obstet Gynecol 18(1):8-13

23. Morice $P$ et al (2004) First case of a centropelvic recurrence after radical trachelectomy: literature review and implications for the preoperative selection of patients. Gynecol Oncol 92 (3): 1002-1005

24. Raatz D, Börner P (2000) Disease-free survival and recurrence after laparoscopically-assisted radical vaginal hysterectomy for cervical cancer. Geburtsh Frauenheilk 60:564-568

25. Ackermann S, Beckmann MW (2005) Does cervical cancer therapy in Germany correlate with the German clinical practice guidelines?-A survey of the Arbeitsgemeinschaft Gynaekologische Onkologie (AGO). Geburtsh Frauenheilk 65:164-171

26. Rob L et al (2007) Less radical fertility-sparing surgery than radical trachelectomy in early cervical cancer. Int $\mathrm{J}$ Gynecol Cancer 17(1):304-310

27. Schneider A, Possover M, Kohler C (2001) New concepts for staging and therapy of cervix cancer by endoscopic surgery. Zentralbl Gynakol 123(5):250-254 